\title{
UCRL-JC-121878 \\ PREPRINT \\ Covf $-950846--45$ \\ Generation of Pseudotachylites in Shock Experiments: Implications for Impact Cratering Products and Processes
}

\author{
1995 APS Topical Conference on \\ "Shock Compression of Condensed Matter" \\ August 13-18, 1995 \\ Shearton Seattle Hotel \& Towers \\ Seattle, WA, USA \\ RECEIVED \\ OCT 061995 \\ OSTI
}

P.S. Fiske, W.J. Nellis, H. Lorenzana,

M. Lipp, M. Kikuchi, and Y. Syono

This document was prepared for submittal to

Shock Compression of Condensed Matter

August 9, 1995

This is a preprint of a paper intended for publication in a journal or proceedings. Since - changes may be made before publication, this preprint is made available with the - understanding that it will not be cited or reproduced without the permission of the author. 


\section{DISCLAIMER}

This document was prepared as an account of work sponsored by an agency of the United States Government. Neither the United States Government nor the University of California nor any of their employees, makes any warranty, express or implied, or assumes any legal liability or responsibility for the accuracy, completeness, or usefulness of any information, apparatus, product, or process disclosed, or represents that its use would not infringe privately owned rights. Reference herein to any specific commercial products, process, or service by trade name, trademark, manufacturer, or otherwise, does not necessarily constitute or imply its endorsement, recommendation, or favoring by the United States Government or the University of California. The views and opinions of authors expressed herein do not necessarily state or reflect those of the United States Government or the University of California, and shall not be used for advertising or product endorsement purposes. poses. : : 


\section{DISCLAIMER}

Portions of this document may be illegible in electronic image products. Images are produced from the best available original document. 


\title{
GENERATION OF PSEUDOTACHYLITES IN SHOCK EXPERIMENTS: IMPLICATIONS FOR IMPACT CRATERING PRODUCTS AND PROCESSES
}

\author{
P. S. Fiske ${ }^{a}$, W. J. Nellis ${ }^{a}$, H. Lorenzana ${ }^{a}$, M. Lipp ${ }^{a}$, M. Kikuchi ${ }^{b}$, Y. Syono ${ }^{b}$ \\ ${ }^{a}$ L-299, Lawrence Livermore National Laboratory, Livermore, CA 94550, U.S.A. \\ ${ }^{\mathrm{b}}$ Institute for Materials Research, Tohoku University, Katahira 2-I-I, Aoba-ku, Sendai 980, JAPAN
}

\begin{abstract}
Meteorite impacts produce enormous pressure and strain in rocks. While the role of pressure on the formation of shock metamorphic features has been well studied, the role of strain and strain rate has not been fully appreciated. We shock loaded single-crystal quartz in Al capsules up to $56 \mathrm{GPa}$ using a novel capsule design that allows for significant strain of the sample but $100 \%$ recovery of material. We have made features analogous to type A pseudotachylites at pressures of $42-56 \mathrm{GPa}$. These pseudotachylites contain $\mathrm{Al}, \mathrm{Si}$ and minor $\mathrm{Al}_{2} \mathrm{O}_{3}$ in a matrix of $\mathrm{SiO}_{2}$ glass and cut the sample along radial and concentric fractures. Our results suggest that strain heating is an important energy sink in the formation of large impact craters.
\end{abstract}

\section{INTRODUCTION}

Rocks from impact craters have a variety of distinctive microscopic and macroscopic "shock features" formed by the impact. Some shock features, such as shocked quartz, are found in rocks from both large and small craters have been synthesized in laboratory shock experiments (1). Other features, however, such as shatter cones and pseudotachylites (2), are difficult or impossible to reproduce in laboratory shock experiments and are found in abundance only in larger impact structures, suggesting a significant dependence on scale. While the pressures experienced by rocks in small and large impacts are comparable, the principal difference is in the amount of strain to which the rocks are subjected.

We have conducted a series of experiments (3) using novel shock recovery systems that enable us to vary the strain experienced by the sample during shock-loading. Our experiments have produced glassy veins of black material in quartz that are analogous to pseudotachylites found in the central portion of large impact craters and suggest that the strain produced by large impacts may cause substantial heating of the rocks below the crater floor.

\section{EXPERIMENTAL PROCEDURE}

Disks of high-purity, synthetic, single-crystal quartz were tightly enclosed in $\mathrm{Al}$ and steel capsules and shock-loaded to $42-56 \mathrm{GPa}$ using the $6.5 \mathrm{~m}$ twostage light-gas gun at Lawrence Livermore National Laboratory. Our experiments employ a sample container similar in geometry to those used in previous studies (4) but made of aluminum instead of steel. The sample and capsule are contained by a large fixture made of a strong titanium alloy. Aluminum, with a density of $2.7 \mathrm{~g} / \mathrm{cm}^{3}$ has a shock impedance much closer to that of silicates (in this case quartz, density of $2.65 \mathrm{~g} / \mathrm{cm}^{3}$ ) than of steel. The shock impedance match produces a single loading pulse in the sample, rather than a reverberation or "ring up" to high pressure as is the case with silicates held in steel capsules.

This single wave loading produces a greater rise in temperature than the quasi-isentropic loading of a ring-up experiment and more realistically approximates the single-shock pressure rise during meteorite impact. Lateral deformation of the sample takes place on release from high pressure, analogous to the excavation stage of crater development. The critical feature of the aluminum capsule is its lower strength as compared to steel. Despite being held in 
the strong Ti-alloy fixture, samples held in aluminum capsules undergo more than twice the radial strain of samples held in steel and shocked to the same pressure (Fig. 1).

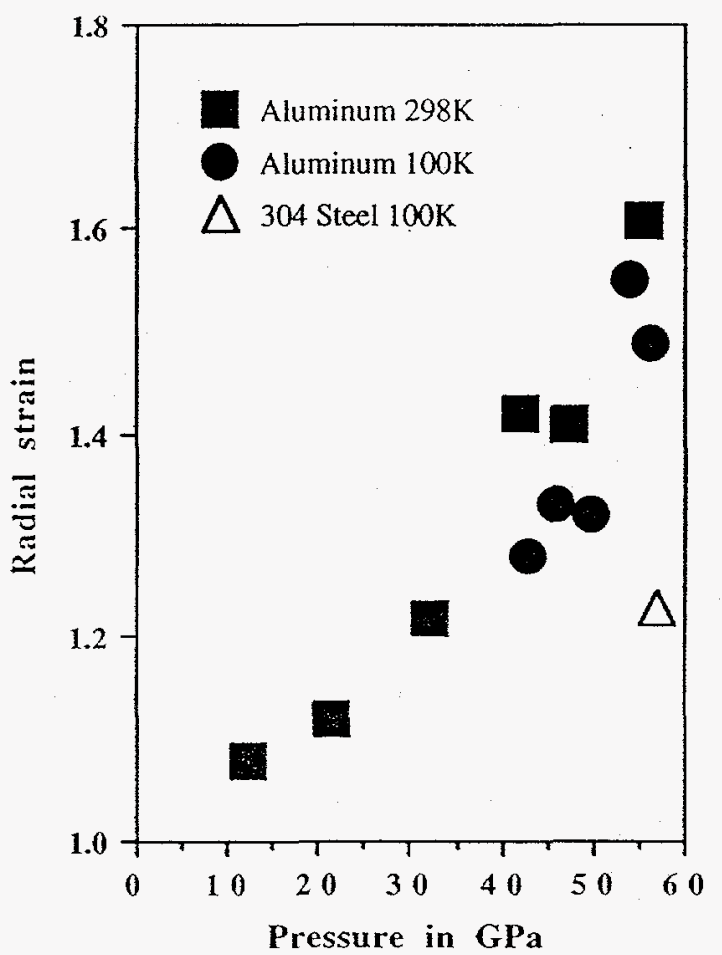

Figure 1. Radial strain of quartz samples held in Al capsules at room T (black squares), held in Al at $100 \mathrm{~K}$ (black circles), and held in steel at room $T$ (open triangle). Strain is measured as the ratio of the final to the initial diameter of the sample.

\section{RESULTS}

Samples recovered from aluminum capsules consist of transparent amorphous $\mathrm{SiO}_{2}$ cut by radial and concentric veins that are filled with a black glassy material (Fig, 2). The transparent regions of the sample show variable low birefringence under crosspolarized light indicating significant residual strain in the amorphous material. The regions with the highest birefringence have the densest spacing of veins. Overall, the density of veins increases with pressure. In contrast, a sample shock-loaded to $56 \mathrm{GPa}$ in steel capsules is transparent throughout, shows no birefringence under cross-polarized light, and has only a few small, irregular fractures that are localized in the central portion of the sample (Fig.
2). The total radial strain (final diameter over initial diameter) of the $56 \mathrm{GPa}$ sample held in Al was 1.6 whereas it was only 1.2 for the sample held in steel and shock-loaded to the same pressure.

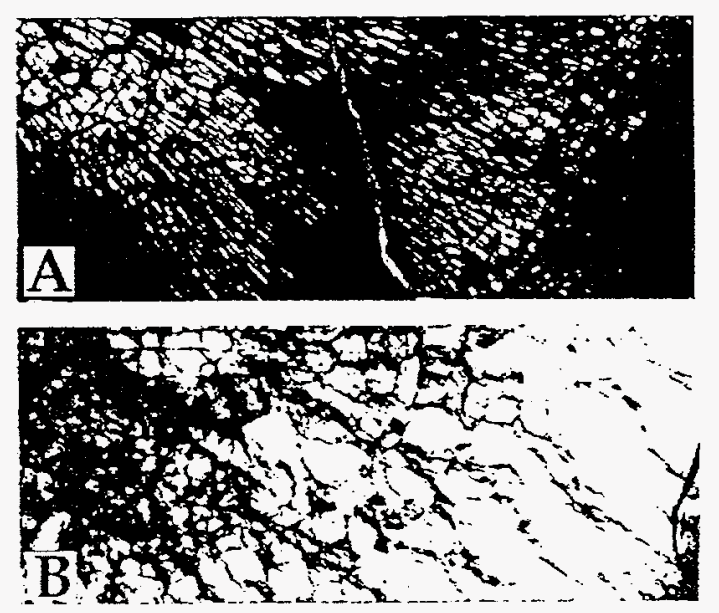

Figure 2. Transmitted light image of portions of three disks of shock-loaded cross-cut quartz viewed in the direction of shock wave propagation. Images are $7 \mathrm{~mm}$ by $2 \mathrm{~mm}$. The center of each disk is in the upper left comer, and the edge is in the lower right corner.

(A) Shock loaded to $56 \mathrm{GPa}$ in Al. The sample consists of clear regions of strained amorphous $\mathrm{SiO}_{2}$ cut by radial and concentric veins filled with black glass. This sample contains $1-2 \%$ Si by weight.

(B) Shock-loaded to $56 \mathrm{GPa}$ in steel. Sample is optically clear with a few irregular fractures in the center of the disk. No Si was detected in this sample.

Analyses of the samples by X-ray diffraction and Raman spectroscopy show that the black glass consists of a mixture of nanocrystalline $\mathrm{Al}$ and $\mathrm{Si}$ and amorphous $\mathrm{SiO}_{2}$. The amount of $\mathrm{Si}$ and $\mathrm{Al}$ increases with pressure, with the highest pressure sample containing $1-2 \%$ Si by weight. TEM images (Fig. 3) and electron diffraction patterns confirm the presence of $\mathrm{Si}$ and $\mathrm{Al}$, along with a small proportion of $\mathrm{Al}_{2} \mathrm{O}_{3}$, and show that the $\mathrm{Si}$ and $\mathrm{Al}$ occur as round clasts 10 to $400 \mathrm{~nm}$ in size in a matrix of amorphous $\mathrm{SiO}_{2}$. The melting of $\mathrm{SiO}_{2}$ provides a lower limit on the temperature of the pseudotachylite in our experiments $(2000 \mathrm{~K}$ at $\mathrm{P}=0)$ and these temperatures are similar to those required to reduce $\mathrm{SiO}_{2}$ in soils struck by lightning (5). 


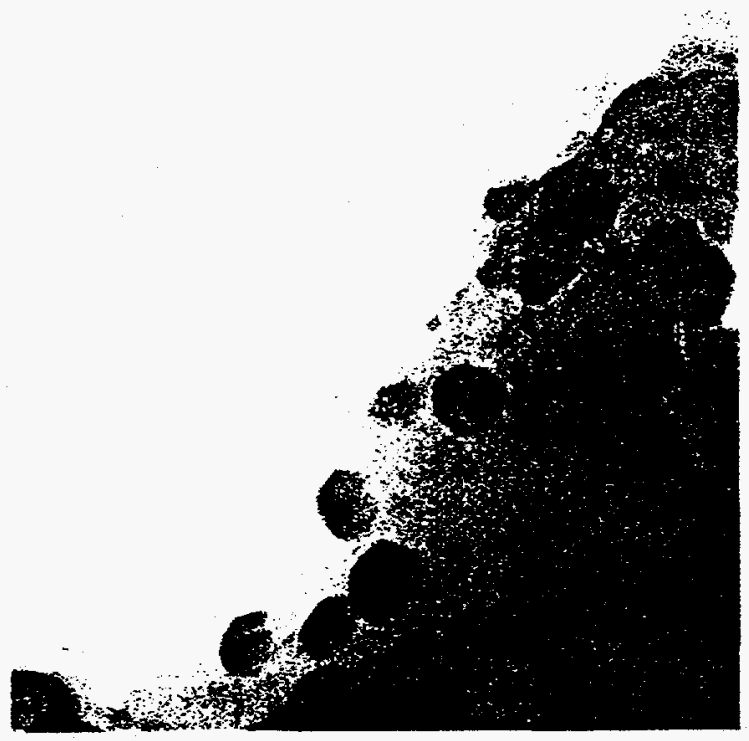

Figure 3. Transmission electron microscope image of black glass formed in quartz shock-loaded to $46 \mathrm{GPa}$ in Al. The black glass consists of spheres of crystalline $\mathrm{Si}$ and $\mathrm{Al}$ (which appear darker in this image) in a matrix of $\mathrm{SiO}_{2}$ glass. Crystallites range in size from 20 to $400 \mathrm{~nm}$.

\section{DISCUSSION}

Our results suggest that plastic deformation and the production of pseudotachylites may be an important and little appreciated process in meteorite impacts. Our highest pressure sample contained $1-2 \% \mathrm{Si}$ by weight. TEM images suggest that the $\mathrm{Si}$ represents roughly $10-20 \%$ of the volume of pseudotachylite-like material produced. Thus a substantial fraction of the total sample may have been pseudotachylite. The formation of dense networks of type A pseudotachylites in the central proportions of impact structures may similarly leave the rocks significantly hotter than that predicted from Hugoniot measurements or post-shock temperature measurements. This may cause the central portions of large impact structures to have a substantial static thermal metamorphic overprint. In addition, friction melting may be an important contribution to the total volume of impact melt in larger craters and may explain the reported increase in the proportion of impact melt with crater size (6).

Shock wave profile measurements show that quartz shock-loaded above the dynamic elastic limit (12 GPa) is nearly strengthless on release from high pressure (7). The formation and persistence of meltlubricated fractures may be a principal contributor to the loss of strength on pressure release, and the formation of type A pscudotachylites during compression and crater excavation may substantially weaken the basement rock in the center of the crater and allow for nearly hydrostatic rebound of the crater floor.

Finally, shear heating and the formation of pseudotachylites might have a significant effect on estimations of shock devolatilization of planetary materials based on shock experiments. Experiments employing steel capsules (8) may have prevented significant strain of the sample thus producing lower temperatures and an underestimation of the amount of shock devolatilization with pressure. Furthermore, numerical modeling of cometary impacts (9) may underestimate the role of strain heating in the projectile and thus may overestimate the potential for delivery of organic material by impact.

Work at LLNL was performed under the auspices of the $U$. S. Department of Energy under Contract No. W-7405Eng-48.

\section{REFERENCES}

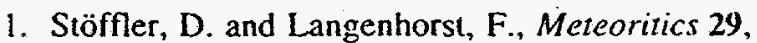
155-181 (1994).

2. Thompson, L. M., and Spray, J. G., in Large Meteorite Impacts and Planetary Evolution, B. O. Dressler, R. A. F. Grieve, V. L. Sharpton, Eds. (Geological Society of America, Boulder, Co., 1994), vol. 293, pp. 275-288.

3. Fiske, P. S., Nellis, W. J., Lipp, M., Lorenzana, H., Kikuchi, M., and Syono, Y., Science (submitted).

4. Cordier, P. et al., Phys. Chem. Min. 21, 133-139 (1994).

5. Essene, E. J., and Fisher,D. C., Science 234, 189193 (1986)

6. Grieve, R. A. F., and Cintala, M. J., Meteoritics 27, 526-538 (1992).

7. Grady, D. E., J. Geophys. Res., 85, 913-924 (1980).

8. Chen, G., Tyburczy, J. A., and Ahrens, T. J., Earth Planet. Sci. Lett. 128, 615-628 (1994).

9. Chyba, C. F., Thomas, P. J.; Brookshaw, L., and Sagan, C., Science 249, 366-373 (1990). 